\title{
COVID-19: the older adult and the importance of vitamin D sufficiency
}

\author{
Paula M. O’Shea ${ }^{1}$ (D), Tomás P. Griffin ${ }^{2}$, Michelle Brennan ${ }^{3}$ and Eamon C. Mulkerrin ${ }^{3}$ \\ ${ }^{1}$ Department of Clinical Biochemistry, Saolta University Health Care Group (SUHCG), Galway University Hospitals, Newcastle Road, Galway, \\ Ireland \\ ${ }^{2}$ Centre for Endocrinology, Diabetes and Metabolism, SUHCG, Galway University Hospitals, Galway, Ireland \\ ${ }^{3}$ Department of Geriatric Medicine, University Hospital Galway, Co., Galway, Ireland
}

(Received 17 August 2020 - Accepted 18 August 2020)

Journal of Nutritional Science (2020), vol. 9, e40, page 1 of 5

doi: $10.1017 /$ jns.2020.36

Abstract

In December 2019, in Wuhan, China, the novel coronavirus 'severe acute respiratory syndrome 2' (SARS-CoV-2) was discovered as the cause of a pneumonia-like illness and subsequently named coronavirus disease 2019 (COVID-19). COVID-19 spread and is now a global pandemic. With few exceptions, countries in the Northern hemisphere have higher mortality rates from COVID-19. This may be due to an increased prevalence of older people in Northern Europe at higher risk of having cardio-pulmonary and metabolic comorbidities as well as hypovitaminosis D. With increasing age, immunosenescence and 'inflammaging' lead to impaired and maladaptive immune responses to SARS-CoV-2 infections, contributing to the enhanced prevalence of severe COVID-19 in older patients. The association of ageing with increased vitamin D deficiency, which is associated with cardiovascular risk factors and disease and worse prognosis in COVID-19 infection, is discussed. Considerable experimental evidence demonstrates the immuno-modulatory properties of vitamin $\mathrm{D}$, in particular, its role in regulating and suppressing the inflammatory cytokine response to viral respiratory infections links the importance of vitamin D sufficiency as a potential protective factor in COVID-19. There is an urgent need for prospective randomised studies to examine whether hypovitaminosis D correlates with severity of COVID-19 disease and the actual benefit of repletion. Moreover, given what has been described as a 'pandemic of vitamin D deficiency', especially in Europe, and in the context of the SARS-CoV-2 contagion, the authors support the call for public health doctors and physicians, with support from Governments, to prioritise and strengthen recommendations on vitamin D intake and supplementation.

Key words: COVID-19: Vitamin D sufficiency: Vitamin D deficiency: Older adult

In December 2019, in Wuhan, China, the novel coronavirus 'severe acute respiratory syndrome 2' (SARS-CoV-2) was discovered as the cause of a pneumonia-like illness ${ }^{(1)}$ and subsequently named coronavirus disease 2019 (COVID-19) $^{(2)}$. COVID-19 spread and is now a worldwide pandemic ${ }^{(3)}$. Globally, SARS-CoV-2 has infected $20,439,814$ people and resulted in 744,385 deaths (13 August 2020) ${ }^{(4)}$. In a retrospective Chinese multicentre cohort study, multivariable regression analysis determined that older age was associated with an increased odds of in-hospital death (OR 1.10;95\% CI: $1.03,1 \cdot 17$, per year increase; $p=0 \cdot 0043)^{(5)}$. While older people do not appear to be at an increased risk of contracting
COVID-19, they are more vulnerable to developing serious complications and have the highest mortality rate ${ }^{(5-7)}$. Many older people have comorbidities such as cardiovascular disease, diabetes and frailty that deplete their reserves and weaken their immune response ${ }^{(8)}$. Moreover, hospitalised patients with concomitant cardiac disease and COVID-19 have an extremely poor prognosis compared to those without a history of cardiac disease ${ }^{(9)}$.

However, increases in these comorbidities alone do not fully explain the preponderance of particularly severe COVID-19 infections in older people. Through the process known as immunosenescence, the immune system, including its ability

* Corresponding author: Paula M. O’Shea, email PaulaM.OShea@hse.ie

(C) The Author(s), 2020. Published by Cambridge University Press on behalf of The Nutrition Society. This is an Open Access article, distributed under the terms of the Creative Commons Attribution-NonCommercial-NoDerivatives licence (http://creativecommons.org/licenses/by-nc-nd/4.0/), which permits non-commercial re-use, distribution, and reproduction in any medium, provided the original work is unaltered and is properly cited. The written permission of Cambridge University Press must be obtained for commercial re-use or in order to create a derivative work. 
to recognise, activate the system, obliterate and remove a virus such as SARS-CoV-2, is impaired in an extremely unpredictable fashion with increasing age ${ }^{(10,11)}$. There is an ongoing debate over which of these tasks is most important to the progression of COVID-19 in a given older individual ${ }^{(12)}$. Both innate (reduced pathogen recognition and recruitment of macrophages) and adaptive (atrophy of the thymus with dysfunctional memory lymphocytes) immunity become defective in older age. Moreover, a chronic increase in systemic inflammation, known as 'inflammaging', thought to arise from an overactive but less effective immune alerting system is more prominent with increasing age ${ }^{(13)}$. There is impressive evidence that 'inflammaging' in association with sedentary lifestyle habits, obesity and nutritionally unbalanced diets is a major driver of cytokine storm which is associated with up to half of the fatalities in COVID-19 infections ${ }^{(14,15)}$.

The main physiological causes of vitamin $\mathrm{D}$ insufficiency are lack of exposure to sunlight (UVB radiation at 290-315 nm), the concentration of melanin in the skin, and as we age, the decreased capacity of human skin to synthesise vitamin $\mathrm{D}^{(16,17)}$. Vitamin $\mathrm{D}$ deficiency is associated with incident cardiovascular disease ${ }^{(18)}$, increased risk of ischemic heart disease and early death ${ }^{(19)}$, although supplementation has not been shown to reduce the risk of invasive cancer or cardiac events $^{(20)}$. The VITAL authors conclude that although their study did not show a benefit of supplementation it remains plausible that a study exploring the effects of supplementation in those with extremely low 25(OH)D ( $<50 \mathrm{nmol} / \mathrm{l})$ could illustrate a benefit; however, maintaining blinded groups 25 $(\mathrm{OH}) \mathrm{D}(<50 \mathrm{nmol} / \mathrm{l})$ for a long period would not be ethical so this research question will remain difficult to answer ${ }^{(20)}$.

Ecological studies have attributed the reported higher rates of coronary heart disease and hypertension to the higher prevalence of vitamin $\mathrm{D}$ deficiency in regions at increasing distance from the equator ${ }^{(18)}$. Striking differences in mortality rates from COVID-19 have been reported between countries at different latitudes worldwide, with those in the Northern hemisphere having higher mortality rates ${ }^{(21)}$. On 3 April 2020 , the death rate per million of the population in the United Kingdom was reported as sixty-eight compared to two in Australia reported one week later ${ }^{(22)}$. The higher mortality rates observed in countries that lie above $35^{\circ}$ North may be due to an increased prevalence of older people in Northern Europe, who have higher risk of having cardio-pulmonary and metabolic comorbidities ${ }^{(21)}$ as well as those with vitamin D deficiency, especially during the winter months when 25 $(\mathrm{OH}) \mathrm{D}$ levels are lowest ${ }^{(17,23,24)}$. Exceptions include countries like Brazil and Mexico, which serves to emphasise the multifactorial nature of control of COVID-19 related morbidity and spread. In particular, these outliers highlight the vital importance of excellent public health measures including hand hygiene, respiratory etiquette, ability to test and trace, social isolation, as well as availability and correct use of personal protection equipment ${ }^{(25)}$.

Evolution of SARS-CoV-2 to infect humans is thought to have resulted from mutations in its spike glycoprotein, the mechanism through which it enters cells, and in the nucleocapsid $\mathrm{N}$ protein which regulates viral replication and transcription $^{(26)}$. Vitamin D can potentially reduce the risk of infections by inducing antimicrobial and host defence peptides (cathelicidins and defensins) that can lower viral replication rates. Reduced concentration of pro-inflammatory cytokines occurs which produce inflammation injurious to the lining of the lungs resulting in pneumonia, and Vitamin D also increases the concentration of anti-inflammatory cytokines ${ }^{(27)}$. While the virulence mechanism of SARS-CoV-2 has yet to be fully elucidated, it has recently been demonstrated that human dipeptidyl peptidase-4 receptor (DPP-4/CD26) binding interacts with the $\mathrm{S} 1$ domain of the SARS-CoV-2 spike glycoprotein, suggesting that it may be an important virulence factor in SARS-CoV-2 infection ${ }^{(28)}$. Importantly, correction of vitamin $\mathrm{D}$ deficiency has been shown to significantly reduce the in vivo expression of the DPP-4/CD26 receptor ${ }^{(29)}$. Vitamin D also reduces the production of IL-6, a pro-inflammatory cytokine, in monocytes ${ }^{(30)}$ which is implicated in the development of the aforementioned cytokine storm, more common in older people and the major contributor to severe COVID-19 infection in many cases ${ }^{(31)}$. A recent meta-analysis which included results from 25 randomised controlled trials ( $n$ 11321), determined that regular daily vitamin D2/D3 supplementation of up to 2000 IU reduced the risk of acute respiratory tract infection among all participants (adjusted odds ratio (AOR) 0.88; 95\% CI: $0 \cdot 81,0 \cdot 96 ; p<0 \cdot 001)$ and was safe ${ }^{(32)}$.

The protective effects of supplementation with vitamin $\mathrm{D}$ were stronger in those with baseline $25(\mathrm{OH}) \mathrm{D}$ levels $<25$ nmol/1 (AOR 0.30; $95 \%$ CI: 0.17, 0.53; $p<0 \cdot 001$ ) when compared to those with a baseline $25(\mathrm{OH}) \mathrm{D}$ levels $\geq 25 \mathrm{nmol} / 1$ (AOR 0.75; $95 \%$ CI: 0.60, 0.95; $p=0 \cdot 006)^{(32)}$. However, considerable heterogeneity in the trial results observed most likely due to the differences in study settings, vitamin D supplemental dose, definitions of acute respiratory tract infection and inclusion of populations with pre-existing respiratory disease, may limit the generalisability of these findings ${ }^{(33)}$.

Autier et al. systematically reviewed meta-analyses of vitamin D supplementation and non-skeletal disorders published between 1 January 2013 and 31 May 2017 that included study participants of all ages, including pregnant women. They indicated that vitamin D supplementation may help to prevent common upper respiratory tract infections and asthma exacerbations $^{(34)}$. Rejjnmark et al. systematically reviewed the characteristics of 30 randomized clinical trials included in seven meta-analyses on non-skeletal effects of vitamin D supplementation $^{(35)}$. In four of the seven meta-analyses evaluated benefit was not observed, while in three, the authors found that the risk of respiratory tract infection was likely to be attenuated by vitamin D supplementation; in particular, for those with a low baseline serum $25(\mathrm{OH}) \mathrm{D}$ concentration. It should be appreciated that for individuals with minimal or no exposure to sunlight, the Scientific Advisory Committee on Nutrition (SACN) in the United Kingdom (UK) recommends vitamin D supplementation of $10 \mu \mathrm{g}$ (400 IU) daily to maintain 25OHD concentrations above $25 \mathrm{nmol} / 1$ (the level required to protect musculoskeletal health in the majority of the population) over an entire year ${ }^{(36)}$.

Vitamin $\mathrm{D}$ supplementation has been shown to increase $\mathrm{T}$ helper $\left(\mathrm{CD}^{+}\right)$cells that play a key role in the adaptive immune 
system in HIV infection ${ }^{(37)}$. Venous thromboembolism is common in those with severe COVID-19 infection ${ }^{(38,39)}$ and hypovitaminosis $\mathrm{D}$ has been reported to correlate with increased thrombosis, which may reflect a direct aetiological effect of vitamin D deficiency or be a surrogate marker of relative immobility for those at most risk ${ }^{(40,41)}$. Furthermore, protracted activation of the renin-angiotensin-aldosterone system may contribute to chronic cardiorespiratory disease with decreased lung function in patients with hypovitaminosis $\mathrm{D}^{(42)}$.

Older adults are at increased risk of vitamin D deficiency and they produce $75 \%$ less cutaneous vitamin D3 than young adults, even with regular sun exposure ${ }^{(43)}$. Intestinal resistance to $1,25(\mathrm{OH})_{2} \mathrm{D}$ develops with increasing age, leading to impaired intestinal absorption of calcium associated with reduced numbers of vitamin $\mathrm{D}$ receptors. The age-related reduction in renal function impairs vitamin $\mathrm{D}$ activation ${ }^{(44)}$. Other risk factors for vitamin $\mathrm{D}$ deficiency include reduced oral intake, nutritionally deficient diets, limited sun exposure, hepatic and renal impairment, together with some antiepileptic medications, all of which occur more frequently in older people, with residents of care institutions at particular risk ${ }^{(45)}$.

Vitamin D deficiency is a major global health problem ${ }^{(46,47)}$, worse in Northern latitudes ${ }^{(21,48)}$ without good programmes for supplementation of vitamin $\mathrm{D}$ or fortification of foodstuffs, as occurs in some Nordic countries with reduced mortality from COVID-19 ${ }^{(49)}$. Ireland is no exception, with new research from the Irish Longitudinal Study on Ageing (TILDA) reporting similar high rates of vitamin D deficiency $(25(\mathrm{OH}) \mathrm{D}:<30 \mathrm{nmol} / \mathrm{l})$ in both men and women during the winter: $21 \cdot 3 \%(n 244,209)$ in those aged over 55 years, $29 \cdot 6$ $\%(n 23,987)$ for those between 80 and 84 years and $46 \cdot 6 \%(n$ $31,480)$ in those aged $>85$ years ${ }^{(49)}$. Deficiency was particularly severe in the West of Ireland with a rate of $59 \cdot 5 \%(n 8,738)$ in those $>85$ years. The latter finding of low vitamin D status amongst older adults is corroborated by our group ${ }^{(17,50-52)}$. Moreover, high prevalence rates of vitamin $\mathrm{D}$ deficiency were more common in nursing homes $(\mathrm{NH})$ residents $(50.5 \%$, $n 138)$ and inpatients $(45 \cdot 1 \%, n 1,055)$ compared to patients in the community $(20 \cdot 3 \%, n 3,101)$ or outpatients $(24.5 \%$, $n 1,585)^{(24)}$. Interestingly, almost $50 \%$ of all deaths due to COVID-19 in Ireland involve residents of $\mathrm{NHs}^{(53)}$. It is also worth highlighting that the 'cocooning' strategy advocated by the Irish government serves to further reduce access to sunlight (UVB) for those most at risk with potential exacerbation of vitamin D deficiency. Recent meta-analyses of randomised controlled trials concluded that the use of vitamin D supplements was associated with lower total mortality in elderly, predominantly vitamin D deficient participants ${ }^{(54,55)}$. Together, this evidence provides a rationale for vitamin D supplementation in those with vitamin $\mathrm{D}$ deficiency or at risk of vitamin D deficiency with a view to ameliorating the severity, complications and poor outcomes for those with COVID-19 disease ${ }^{(48,50)}$.

While it is important to supplement with vitamin D during times of self-isolation with minimal exposure to sunlight, the public need to be counselled against the use of high doses of vitamin D which may be harmful and where there is no evidence of benefit. Prescribing high dose vitamin $\mathrm{D}$ is the domain of clinical practice ${ }^{(56)}$. Critically, advice given to the public should be evidenced-based, accurate, clear, accessible, timely and aligned to government recommendations. There is a variance in country-specific recommendations, UK: $400 \mathrm{IU} / \mathrm{d}^{(36)}$, United States of America (USA) ${ }^{(57)}$ and European Union $(\mathrm{EU})^{(58)}$ : $600 \mathrm{IU} / \mathrm{d} \quad(800 \mathrm{IU} / \mathrm{d}>70$ years) ${ }^{(59)}$. In June, Public Health England (PHE) issued an advisory statement informing of the absence of evidence to support taking vitamin D supplements to specifically prevent or treat COVID-19 $9^{(60)}$. This advice re-enforced the position statements from the SACN report published in $2016^{(36)}$ and recommended that all people should continue to follow UK Government advice on daily vitamin D supplementation to maintain bone and muscle health during the COVID-19 pandemic.

As considerable experimental evidence demonstrates the immuno-modulatory properties of vitamin $\mathrm{D}$ and in particular, its role in regulating and suppressing the inflammatory cytokine response to viral respiratory infections ${ }^{(61-64)}$, there is an urgent need for future prospective studies to examine whether hypovitaminosis D correlates with severity of COVID-19 disease ${ }^{(22)}$. Randomised controlled trials evaluating the impact of vitamin $\mathrm{D}$ therapy on the course of COVID-19 and the potential of optimisation of vitamin D status to benefit patient outcomes are warranted. Furthermore, given what has been described as a 'pandemic of vitamin D deficiency', especially in Europe ${ }^{(65)}$ and in the context of the SARS-CoV-2, the authors support the call for public health doctors and physicians, with support from Governments, to prioritise and strengthen recommendations on vitamin $\mathrm{D}$ intake and supplementation $^{(22,49,56)}$.

\section{Acknowledgements}

The author(s) declared no potential conflict of interest that could be perceived as prejudicing the impartiality of the research, authorship, and/or publication of this article.

The authors received no financial support for this commentary.

P.M.O.S. researched the literature and wrote the first draft of the manuscript. T.P.G., M.B. and E.C.M. critically revised and approved the final version of the manuscript.

\section{References}

1. Phelan AL, Katz R \& Gostin LO (2020) The Novel Coronavirus originating in Wuhan, China: challenges for Global Health Governance. $J A M A$ 323, 709-710.

2. Chan JW, Ng CK, Chan YH, et al. (2003) Short term outcome and risk factors for adverse clinical outcomes in adults with severe acute respiratory syndrome (SARS). Thorax 58, 686-689.

3. World Health Organization (WHO) (2020) WHO DirectorGeneral's opening remarks at the media briefing on COVID-19 11 March 2020. https://www.who.int/dg/speeches/detail/whodirector-general-s-opening-remarks-at-the-media-briefing-on-covid-1911-march-2020 (accessed 27 June 2020).

4. World Health Organization (WHO) (2020) Coronavirus disease 2019 (COVID-19) Situation Report - 206. https://www.who.int/ docs/default-source/coronaviruse/situation-reports/20200813-covid19-sitrep-206.pdf?sfvrsn=bf38f66b_6 (accessed 14 August 2020). 
5. Zhou F, Yu T, Du R, et al. (2020) Clinical course and risk factors for mortality of adult inpatients with COVID-19 in Wuhan, China: a retrospective cohort study. Lancet 395, 1054-1062.

6. Chen T, Wu D, Chen H, et al. (2020) Clinical characteristics of 113 deceased patients with coronavirus disease 2019: retrospective study. BMJ 368, m1091.

7. Huang C, Wang Y, Li X, et al. (2020) Clinical features of patients infected with 2019 novel coronavirus in Wuhan, China. Lancet 395, 497-506.

8. Sinclair AJ \& Abdelhafiz AH (2020) Age, frailty and diabetes - triple jeopardy for vulnerability to COVID-19 infection. EClinicalMedicine 22, 100343. https://www.thelancet.com/action/showPdf?pii=S2589$5370 \% 2820 \% 2930087-0$ (accessed 20 Jul 2020).

9. Inciardi RM, Adamo M, Lupi L, et al. (2020) Characteristics and outcomes of patients hospitalized for COVID-19 and cardiac disease in Northern Italy. Eur Heart J 41, 1821-1829.

10. Fulop T, Larbi A, Dupuis G, et al. (2017) Immunosenescence and inflamm-aging as two sides of the same coin: friends or foes? Front Immunol 8, 1960.

11. Franceschi C, Salvioli S, Garagnani P, et al. (2017) Immunobiography and the heterogeneity of immune responses in the elderly: a focus on inflammaging and trained immunity. Front Immunol 8, 982.

12. Shen-Orr SS \& Furman D (2013) Variability in the immune system: of vaccine responses and immune states. Curr Opin Immunol 25, $542-547$.

13. Franceschi C, Bonafe M, Valensin S, et al. (2000) Inflamm-aging: an evolutionary perspective on immunosenescence. Ann N Y Acad $S_{c i}$ 908, 244-254.

14. Sanada F, Taniyama Y, Muratsu J, et al. (2018) Source of chronic inflammation in aging. Front Cardiovasc Med 5, 12.

15. Buford TW, Carter CS, VanDerPol WJ, et al. (2018) Composition and richness of the serum microbiome differ by age and link to systemic inflammation. Geroscience 40, 257-268.

16. MacLaughlin J \& Holick MF (1985) Aging decreases the capacity of human skin to produce vitamin D3. J Clin Invest 76, 1536-1538.

17. Griffin TP, Wall D, Blake L, et al. (2020) Higher risk of vitamin D insufficiency/deficiency for rural than urban dwellers. I Steroid Biochem Mol Biol 197, 105547. https://doi.org/10.1016/j.jsbmb. 2019.105547 (accessed 25 Jul 2020).

18. Wang TJ, Pencina MJ, Booth SL, et al. (2008) Vitamin D deficiency and risk of cardiovascular disease. Circulation 117, 503-511.

19. Brondum-Jacobsen P, Benn M, Jensen GB, et al. (2012) 25-hydroxyvitamin d levels and risk of ischemic heart disease, myocardial infarction, and early death: population-based study and meta-analyses of 18 and 17 studies. Arterioscler Thromb Vasc Biol 32, 2794-2802.

20. Manson JE, Cook NR, Lee IM, et al. (2019) Vitamin D supplements and prevention of cancer and cardiovascular disease. $N$ Engl J Med 380, 33-44.

21. Panarese A \& Shahini E (2020) Letter: Covid-19, and vitamin D Aliment Pharmacol Ther 51, 993-995.

22. Rhodes JM, Subramanian S, Laird E, et al. (2020) Editorial: low population mortality from COVID-19 in countries south of latitude 35 degrees North supports vitamin $\mathrm{D}$ as a factor determining severity. Aliment Pharmacol Ther 51, 1434-1437.

23. Cantorna MT, Snyder L, Lin YD, et al. (2015) Vitamin D and 1,25 $(\mathrm{OH})_{2} \mathrm{D}$ regulation of $\mathrm{T}$ cells. Nutrients 7, 3011-3021.

24. Griffin TP, Wall D, Blake L, et al. (2020) Vitamin D status of adults in the community, in outpatient clinics, in hospital and in nursing homes in the West of Ireland. J Gerontol A Biol Sci Med Sci. https://doi.org/10.1093/gerona/glaa010 (accessed 25 Jul 2020).

25. Biesalski HK (2020) Vitamin D deficiency and co-morbidities in COVID-19 patients - a fatal relationship? NFS Journal 20, 10-21.

26. Benvenuto D, Giovanetti M, Ciccozzi A, et al. (2020) The 2019-new coronavirus epidemic: evidence for virus evolution. J Med Virol 92, 455-459.

27. Grant WB, Lahore H, McDonnell SL, et al. (2020) Evidence that vitamin D supplementation could reduce risk of influenza and COVID-19 infections and deaths. Nutrients 12, 988.
28. Vankadari N \& Wilce JA (2020) Emerging Wuhan (COVID-19) coronavirus: glycan shield and structure prediction of spike glycoprotein and its interaction with human CD26. Emerg Microbes Infect 9, 601-604.

29. Komolmit P, Charoensuk K, Thanapirom K, et al. (2017) Correction of vitamin D deficiency facilitated suppression of IP-10 and DPP IV levels in patients with chronic hepatitis C: a randomised double-blinded, placebo-control trial. PLOS ONE 12, e0174608.

30. Sadeghi K, Wessner B, Laggner U, et al. (2006) Vitamin D3 downregulates monocyte TLR expression and triggers hyporesponsiveness to pathogen-associated molecular patterns. Eur J Immunol 36, 361-370.

31. Mehta P, McAuley DF, Brown M, et al. (2020) COVID-19: consider cytokine storm syndromes and immunosuppression. Lancet 395, 1033-1034.

32. Martineau AR, Jolliffe DA, Hooper RL, et al. (2017) Vitamin D supplementation to prevent acute respiratory tract infections: systematic review and meta-analysis of individual participant data. BMJ 356, i6583.

33. SACN Scientific Advisory Committee on Nutrition (2020) Rapid revien: Vitamin $D$ and acute respiratory tract infections. https://www. gov.uk/government/groups/scientific-advisory-committee-on-nutrition (accessed 14 August 2020).

34. Autier P, Mullie P, Macacu A, et al. (2017) Effect of vitamin D supplementation on non-skeletal disorders: a systematic review of meta-analyses and randomised trials. Lancet Diabetes Endocrinol 5, 986-1004.

35. Rejnmark L, Bislev LS, Cashman KD, et al. (2017) Non-skeletal health effects of vitamin D supplementation: a systematic review on findings from meta-analyses summarizing trial data. PLoS ONE 12, e0180512.

36. SACN Scientific Advisory Committee on Nutrition (2016) Vitamin $D$ and health. https://www.gov.uk/government/groups/scientificadvisory-committee-on-nutrition (accessed 14 August 2020).

37. Alvarez N, Aguilar-Jimenez W \& Rugeles MT (2019) The potential protective role of vitamin D supplementation on HIV-1 infection. Front Immunol 10, 2291.

38. Klok FA, Kruip MJHA, van der Meer NJM, et al. (2020) Incidence of thrombotic complications in critically ill ICU patients with COVID-19. Thromb Res 191, 145-147.

39. Cui S, Chen S, Li X, et al. (2020) Prevalence of venous thromboembolism in patients with severe novel coronavirus pneumonia. $J$ Thromb Haemost 18, 1421-1424.

40. Mohammad S, Mishra A \& Ashraf MZ (2019) Emerging role of Vitamin D and its associated molecules in pathways related to pathogenesis of thrombosis. Biomolecules 9, 649.

41. Bjorkman M, Sorva A \& Tilvis R (2009) Responses of parathyroid hormone to vitamin D supplementation: a systematic review of clinical trials. Arch Gerontol Geriatr 48, 160-166.

42. Shi Y, Liu T, Yao L, et al. (2017) Chronic vitamin D deficiency induces lung fibrosis through activation of the renin-angiotensin system. Sci Rep 7, 3312.

43. Kennel KA, Drake MT \& Hurley DL (2010) Vitamin D deficiency in adults: when to test and how to treat. Mayo Clin Proc 85, 752-757, quiz $757-758$.

44. de Jongh RT, van Schoor NM \& Lips P (2017) Changes in vitamin $\mathrm{D}$ endocrinology during aging in adults. Mol Cell Endocrinol 453, 144-150.

45. Rosen CJ (2011) Clinical practice. Vitamin D insufficiency. N EnglJ Med 364, 248-254.

46. Palacios C \& Gonzalez L (2014) Is vitamin D deficiency a major global public health problem? J Steroid Biochem Mol Biol 144, 138-145.

47. Mithal A, Wahl DA, Bonjour JP, et al. (2009) Global vitamin D status and determinants of hypovitaminosis D. Osteoporos Int 20, 1807-1820.

48. Tian Y \& Rong L (2020) Letter: Covid-19, and vitamin D. Authors' reply. Aliment Pharmacol Ther 51, 995-996. 
49. Laired E, Kenny RA (2020) Vitamin D deficiency in Ireland - implications for COVID-19. Results from The Irish Longitudinal Study on Ageing (TILDA) (accessed 5 May 2020).

50. DeLappe E, McGreevy C, ni Chadhain N, et al. (2006) Vitamin D insufficiency in older female community-dwelling acute hospital admissions and the response to supplementation. Eur J Clin Nutr 60, 1009-1015.

51. Lardner E, Fitzgibbon M, Wilson S, et al. (2011) Hypovitaminosis $\mathrm{D}$ in a healthy female population, aged from 40 to 85 years, in the west of Ireland. Ir J Med Sci 180, 115-119.

52. Delos Reyes J, Smyth A, Griffin D, et al. (2017) Vitamin D deficiency and insufficiency prevalence in the West of Ireland - a retrospective study. J Nutr Health Aging 21, 1107-1110.

53. BBC News (2020) Coronavirus: almost half of Irish Covid-19 deaths in care homes. https://www.bbc.com/news/world-europe52399869 .

54. Bjelakovic G, Gluud LL, Nikolova D, et al. (2014) Vitamin D supplementation for prevention of mortality in adults. Cocbrane Database Syst Rev, 1, CD007470, https://www.cochranelibrary.com/cdsr/ doi/10.1002/14651858.CD007470.pub3/full (accessed 21 Jul 2020).

55. Keum N, Lee DH, Greenwood DC, et al. (2019) Vitamin D supplementation and total cancer incidence and mortality: a metaanalysis of randomized controlled trials. Ann Oncol 30, 733-743.

56. McKenna MJ \& Flynn MAT (2020) Covid-19, cocooning and Vitamin D intake requirements. Ir Med J 113, 79.
57. Institute of Medicine (2011) Dietary Reference Intakes for Calcium and Vitamin D. Washington, DC, USA.

58. European Food Safety Agency (2016) Dietary reference values for vitamin D. EFS A J 14, 4547.

59. Lanham-New S, Webb AR, Cashman KD, et al. (2020) Vitamin D and SARS-CoV-2 virus/COVID-19 disease. BMJ Nutr, Prev Health 3, e000089.

60. NICE National Institute for Health and Care Excellence (2020) COVID-19 rapid evidence summary: vitamin D for COVID-19 (Evidence Summary ES28). https://www.nice.org.uk/advice/es28/ chapter/Advisory-statement-on-likely-place-in-therapy (accessed 14 August 2020).

61. Greiller CL \& Martineau AR (2015) Modulation of the immune response to respiratory viruses by vitamin D. Nutrients 7, 42404270.

62. Telcian AG, Zdrenghea MT, Edwards MR, et al. (2017) Vitamin D increases the antiviral activity of bronchial epithelial cells in vitro. Antiviral Res 137, 93-101.

63. Zdrenghea MT, Makrinioti H, Bagacean C, et al. (2017) Vitamin D modulation of innate immune responses to respiratory viral infections. Rev Med Virol 27, e1909, https://doi.org/10.1002/ rmv.1909 (accessed 10 Jul 2020).

64. Laird E, Rhodes J \& Kenny RA (2020) Vitamin D and inflammation: potential implications for severity of Covid-19. Ir Med J 113, 81.

65. Cashman KD, Dowling KG, Skrabakova Z, et al. (2016) Vitamin D deficiency in Europe: pandemic? Am J Clin Nutr 103, 1033-1044. 